\title{
Inmigrantes extranjeros y vivienda marginal en Madrid
}

\author{
Gloria lora-Tamayo D'OCón *
}

Madrid, la comunidad receptora de inmigrantes extranjeros más importante de España, tiene ya planteado un serio problema de integración con la población procedente de paises del Tercer Mundo y Portugal.

"Los inmigrantes de los países débiles están ampliando la base de la pobreza en Madrid. En su mayoría, los extranjeros del Tercer Mundo están formando parte de los estratos pobres y marginados de la ciudad" (GIMÉNEZ, C. 1992).

El fenómeno se extiende como mancha de aceite a los municipios del área metropolitana, prolongándose hacia el Noroeste, en dirección a la Sierra de Guadarrama.

El uso de caravanas, naves abandonadas y edificios semirruinosos como vivienda y la construcción de chabolas, es una realidad cada vez más corriente en la comunidad. Los antiguos poblados gitanos van siendo "irivadidos" y ocupados por población extranjera - marroquíes y gitanos portugueses, sobre todo-y se crean otros nuevos que amenazan con extenderse en un plazo de tiempo corto.

El problema es en gran medida económico: los elevados precios de los pisos en Madrid, tanto en venta como en régimen de alquiler, junto con la precariedad jurídica, económica y laboral de los llamados «inmigrantes económicos", dificulta su acceso a una vivienda digna. A ello se unen otra serie de condicionantes que agravan la situación.

En este artículo se analizan los factores que llevan a la marginación de una buena parte del colectivo extranjero en la comunidad y los alojamientos y viviendas que ocupan los inmigrantes en situación más pre-

\footnotetext{
* Universidad Complutense de Madrid
} 
caria, así como las medidas administrativas y las políticas de vivienda en marcha o en proyecto.

\section{FACTORES DE MARGINACIÓN DE LA POBLACIÓN INMIGRANTE}

A nivel global, se pueden enumerar una serie de circunstancias que empujan a parte del colectivo inmigrante a la marginación:

- La provisionalidad e inestabilidad jurídica que afecta a gran parte de ellos desde su entrada en el país y que supone una circunstancia díficil de remontar dentro del marco de la legislación vigente, en el caso de inmigrantes sin recursos procedentes de países del Tercer Mundo.

- Ambos factores son causa y efecto a la vez de inseguridad laboral y actúan como un círculo vicioso del que resulta difícil salir. El hecho, por otra parte, de poseer un contrato de trabajo y un status legal en un momento dado -como es el caso de un número crecido de inmigrantes económicos procedentes de países pobres, tras el último proceso de regularización - no asegura la continuidad en este status, ya que, como es sabido, los permisos de trabajo y residencia han de ser renovados periódicamente.

- Esta falta de "papeles" propicia el trabajo en la economía sumergida y toda clase de abusos por parte de los empleadores, repercutiendo gravemente en la economía del inmigrante.

- El problema económico gravita desde el principio en la persona que pone en marcha un proyecto migratorio: el pasaje de avión, la plaza en una patera, la «organización» de la entrada clandestina en España..., operaciones a veces repetidas una y otra vez, ante el rechazo en la frontera, suman cantidades de dinero a restituir a veces muy importantes. En este sentido, además, se denuncia la existencia de redes mafiosas que cobran fuertes sumas por la introducción ilegal de inmigrantes en España. En el caso de la reciente «avalancha» de ciudadanos dominicanos, estas redes han tenido un fuerte protagonismo y son responsables de situaciones de endeudamiento angustiosas entre estos grupos.

- El factor ahorro se suma a la precariedad económica de base del inmigrante. La población procedente de paises pobres fuerza al máximo el ahorro para enviar remesas a los familiares que quedaron en su país y que dependen económicamente de él.

- El desconocimiento del idioma, leyes, usos y costumbres, sitúa al inmigrante en inferioridad de condiciones en relación con la población autóctona, suponiendo una barrera poderosa. Las diferencias culturales y 
religiosas, más acusadas en la población procedente de África, constituyen en muchos casos un freno a la integración.

- Otro factor de gran virulencia en Europa y triste actualidad es el racismo: sin recurrir a noticias sobre episodios de violencia que han tenido lugar en los últimos meses en Madrid, se denuncian casos de trato discriminatorio a individuos de piel oscura. Un ejemplo: los solicitantes de refugio negroafricanos que pernoctaban en la madrileña Plaza de España durante el otoño-invierno de 1990-91, vieron rechazado su proyecto de alojarse en Miraflores de la Sierra y Manjirón, sucesivamente, ante la oposición de los alcaldes y vecinos de ambas localidades, a pesar del apoyo de la Administración. Más recientemente, en el verano de 1991, el propio delegado del gobierno recibió la negativa de 128 pensiones madrileñas a acoger a los refugiados negroafricanos desalojados del albergue de Paseo del Rey - que cerraba para realizar labores de desinfección y desinsección-, a pesar de garantizarse el pago. (El Sol, 22 de julio 1991). Las quejas, a nivel individual, de la población de color, sobre el rechazo que inspiran, son frecuentes. Éste parece suavizarse conforme se «suaviza" el color de la piel.

- Junto a esto, Azedine Gesous, embajador de Marruecos en España, habla de la existencia en nuestro país y más concretamente en Madrid de un "racismo económico", que apunta hacia ciudadanos de otras etnias que tienen escasos recursos y que se complementaría con lo que $\mathrm{C}$. López, asistente social y hermana de la Caridad, denomina urechazo frontal de la pobreza" (El Pais, 22 diciembre, 1992), que incluye, no sólo a extranjeros, sino a los estratos de población que viven en situación precaria. En este sentido, la Encuesta sobre Inmigrantes, realizada recientemente por el Centro de Investigaciones sobre la Realidad Social (CIRES), señala que la discriminación en España más que racial es social. Según los resultados de la encuesta, más de la mitad de los españoles no pondrían objeción alguna a tener inmigrantes como vecinos. El grado mayor de molestia en caso de vecindad estaría encabezado por los drogadictos, seguidos a distancia por gitanos, prostitutas, enfermos de sida, homosexuales, expresidiarios y marroquíes. Al parecer, africanos de raza negra y sudamericanos ocuparian los índices de rechazo más bajos.

- La falta de información y el bajo nivel de instrucción de parte de la población autóctona son causa de desconfianza y rechazo de este colectivo. Entre algunos sectores, postulados como «los inmigrantes vienen a quitarnos nuestros puestos de trabajo" o slogans como «inmigrante: maleante", llegan a asumirse como verdades de fe. En otros, las noticias de la prensa sobre la relación de los extranjeros con redes de prostitución o de delincuencia y con el tráfico de drogas, hacen mella y sirven para 
generalizar una mala opinión de los inmigrantes. Recientemente ha sido señalada la responsalidad de la prensa sensacionalista en la formación de posturas xenófobas entre la población (GIMÉNEZ, C. 1992).

- La adquisición de una vivienda en propiedad en Madrid es difícil, no sólo para los inmigrantes, sino también para la población local, dados los elevados precios del mercado. El acceso a viviendas sociales promocionadas por los ayuntamientos se restringe a los ciudadanos de nacionalidad española. Mientras existan dificultades para alcanzar una vivienda en propiedad por motivos económicos entre la población nacional, resulta cuando menos desaconsejado arbitrar medidas que faciliten la compra de una vivienda a ciudadanos extranjeros de bajos recursos.

- También es difícil para algunos colectivos el acceso a viviendas de alquiler. Los precios son elevados y se suben más cuando el solicitante es inmigrante, sobre todo si es ilegal o de color. La exigencia de presentar una nómina para acceder al piso, es normalmente difícil de satisfacer. Por último, la desconfianza y protestas entre los vecinos, por los ruidos, reuniones, fiestas y el trasiego de personas que muchos pisos ocupados por inmigrantes extranjeros tienen, suele reforzar la resistencia del arrendador a aceptar este tipo de inquilinos. Los siguientes testimonios de personas que se alojan en chabolas son suficientemente expresivos: «Queremos alquilar pisos, pero no quieren, a pesar de que ofrecemos pagar por adelantado. Son caros, pero nosotros podemos juntarnos cuatro o cinco y poner cada uno 20.000 pesetas. Pero cuando se enteran de que somos marroquíes no nos los alquilan" ( $E I$ Mundo, 5 febrero 1992). "A los marroquíes, ni aunque dispusieran de 300.000 pesetas al mes, les alquilarían un piso en Boadilla» (El País Dominical, 22 noviembre 1992); en este último municipio empiezan a aparecer anuncios de alquiler de viviendas con advertencias de “sólo españoles» o «sólo ciudadanos de la CEE». «Nuestro problema es que nadie nos quiere alquilar una casa aquí (Valdemorillo)». (El País, 16 marzo 1992). El Delegado Diocesano de Inmigrantes de Madrid señalaba recientemente que los «inmigrantes están condenados a vivir hacinados o en chabolas, porque se les niega el acceso a una vivienda digna (...). El Gobierno les niega la posibilidad de solicitar viviendas sociales y los particulares, o no quieren alquilar pisos a los extranjeros, 0 , si lo hacen, les cobran precios abusivos" (El Mundo, 9 julio 1992).

- Por último, algunos grupos étnicos escogen un tipo de vida marginal por sus propias costumbres y tradición. Este es el caso de los gitanos portugueses, responsables de la formación de poblados de chabolas importantes en Madrid en los últimos años y familias nómadas de los países del Este, que empiezan a «aparecer» en zonas de la periferia de la ciudad.

De entre los colectivos inmigrantes en Madrid, los de mayor riesgo de marginación, por todo lo expuesto, son aquellos grupos de bajos recursos 
econónicos cuya cultura acuse mayores diferencias con la española; cuyo color de piel sea más oscuro; cuya lengua no sea la nuestra y también aquellos que cuenten con mayor proporción de varones, ya que las mujeres pueden encontrar con facilidad alojamiento en las casas de los empleadores, dedicándose al servicio doméstico.

Marroquíes y gitanos portugueses protagonizan las situaciones de marginación más apremiantes en la Comunidad. A ellos se están uniendo los negroafricanos, cuya entrada en España como solicitantes de asilo y refugio - solicitud denegada en un $95 \%$ de los casos al cabo de unos meses-, está creciendo notablemente. También se unirán dominicanos, de continuar la tendencia al aumento de la inmigración de varones - hasta hace poco era una emigración fundamentalmente femenina- y al crecimiento de la corriente, como parece, dada la consistencia de la red migratoria establecida entre Santo Domingo y España.

\section{VIVIENDA MARGINAL}

La existencia de vivienda marginal constituye un problema de los más graves de la Comunidad de Madrid y condiciona de forma decisiva el éxito de cualquier programa de integración del colectivo extranjero. Una vivienda digna es el primer paso para la integración. La solución del problema es, pues, previa a cualquier otro planteamiento.

Un estudio realizado recientemente para el ayuntamiento de Madrid sobre inmigrantes marginados en el ámbito del municipio (LIZAMA, L. 1992), considera que 4.000 extranjeros se hallan en la capital en situación de marginación extrema, viviendo en chabolas, en la calle, en casas abandonadas, en albergues o hacinadas en pisos alquilados y precisando de instituciones de ayuda social para cubrir sus necesidades básicas.

La cifra calculada se basa precisamente en la población extranjera que acude a estos centros. A ella habría que añadir el número crecido de inmigrantes en situación precaria que no buscan este tipo de ayuda, viviendo al amparo de amigos o compatriotas mejor establecidos.

En el estudio del Ayuntamiento se realiza una encuesta sobre el $10 \%$ del grupo seleccionado. Desde el punto de vista espacial, destacan los distritos Centro y Fuencarral como lugares de asentamiento preferente $(26,24 \%$ y $17,9 \%$, respectivamente), seguidos de Latina $(9,9 \%)$ y Hortaleza $(8,7 \%)$. Moncloa $(14,5 \%)$ y Vallecas $(7,6 \%)$ alcanzaban elevados valores por la presencia de un Albergue de transeúntes del Ayuntamiento en el primero y un Centro de Acogida a Refugiados del INSERSO en el segundo. 
El colectivo encuestado, compuesto en un $86 \%$ por varones, era mayoritariamente joven, con un $85,5 \%$ de población en edades comprendidas entre los 20 y los 39 años. En relación con el estado civil, el $54 \%$ eran solteros, frente a un $38 \%$ de casados y un $8 \%$ en otras situaciones.

Su procedencia era sobre todo africana: el $59,6 \%$ era originario de este continente, y dentro de él más de la mitad procedía de Marruecos, alcanzando este país el $30,4 \%$ del total del colectivo. Secundariamente, los originarios del Medio Oriente y Asia, en general, eran el 22,2\%; de Iberoamérica, el 9,9\% y de Europa del Este y Portugal, el 8,2\%.

Llama la atención el hecho de que únicamente el 3,5\% de la muestra fuera población ilegal, aunque debe tomarse en consideración que la encuesta se realizó pocos meses después de finalizado el proceso de regularización, por el que pasó a la legalidad la mayor parte de la población extranjera en situación irregular. Con todo, es interesante constatar el gran peso de la población cuyo status es el de solicitante de refugio $(41,2 \%)$. En segundo lugar, destaca la población con permiso de residencia y trabajo $(39,7 \%)$ y por último, los refugiados o asilados $(9,5 \%$ y los que poseen tarjeta de residencia $(6,1 \%)$.

De la variable "tipo de vivienda" se concluye que casi la cuarta parte del colectivo inmigrante residente en Madrid capital en mayor situación de marginación, vive en pisos $(24,7 \%)$ en condiciones deficientes de habitabilidad y alto índice de hacinamiento, en su mayoría; el $18,9 \%$ en albergues; el $17,1 \%$ en chabolas; el $13,1 \%$ en pensiones, el $9,1 \%$ en centros de acogida, el $8,2 \%$ en la calle; el $7,5 \%$ en casas abandonadas $y$ el $1,3 \%$ en otros tipos de vivienda.

Resultaría vital la realización de un estudio paralelo referido al conjunto de la CAM. Sin embargo, por el momento no parece posible su ejecución, dada la atomización de competencias por el elevado número de municipios que componen el ámbito.

El INE investiga en el Censo de Población y Viviendas de 1991 los "alojamientos" existentes en la CAM, diferenciándolos de las "viviendas" y dividiéndolos en fijos y móviles. Entre los fijos se cuentan las cuevas, chozas y chabolas. Los móviles están constituidos por remolques, barcos, caravanas, etc. Resulta interesante la cifra provisional de 1.833 alojamientos fijos y 68 móviles en la CAM, que suponen el $16 \%$ y el $12,5 \%$, respectivamente, de los existentes en el conjunto nacional y su suma, el $0,1 \%$ del total de viviendas de la CAM. Sabemos que en la actualidad este tipo de alojamientos son habitados mayoritariamente por inmigrantes extranjeros, marroquíes y gitanos portugueses sobre todo, sin embargo, nos es imposible conocer la proporción. 
El Consorcio para el Realojamiento de la Población Marginada censó en 19862.673 chabolas en el municipio de Madrid, ocupadas en su mayoría por población gitana española. En 1992 la ejecución de un nuevo Censo ponía de manifiesto la permanencia de 446 chabolas «legales", es decir, de las censadas seis años antes, habiéndose erradicado el resto; pero recogía 1.143 chabolas más, «ilegales", creadas en este período y habitadas en su mayoría por población inmigrante extranjera.

Es imposible cuantificar la vivienda marginal en el ámbito de la CAM. No existen datos rigurosos y fiables de las viviendas que albergan a la población inmigrante extranjera de mínimos recursos y sus condiciones de habitabilidad. Esta es, a nuestro juicio, una carencia grave que dificulta extraordinariamente la puesta en marcha de políticas de vivienda y la erradicación del chabolismo. Únicamente se han realizado algunos estudios concretos pero parciales, sobre asentamientos chabolistas, como los de Pitis y Ricote, que tienen una corta vigencia debido a su dinamismo.

La prensa diaria da noticias con frecuencia de las formas de alojamiento de los inmigrantes que viven en la Comunidad de Madrid y los problemas relacionados con ellas.

Una vivienda digna en propiedad o alquiler sería la deseable para cualquier inmigrante. Sin embargo, soluciones provisionales o de emergencia, como la chabola, el albergue o la propia calle, tienden a perpetuarse, funcionando de hecho como alojamientos definitivos.

El diario El País lanzó la noticia en la primavera del pasado año, de la existencia de 5.000 marroquíes que vivían al raso, pernoctando en los campos de los alrededores de la capital. Con anterioridad (invierno 199091) grupos de negroafricanos solicitantes de refugio, sobre todo nigerianos, se instalaron en el paso peatonal subterráneo de la $\mathrm{C} /$ Bailén, junto a la céntrica Plaza de España, al no poder se alojados por Cruz Roja. En octubre de 1991, El País daba cuenta de la presencia de 50 africanos -en su mayoría procedentes de Ghana y Liberia- alojados entre los muros de la antigua Fábrica de Chocolate "La Fortuna", a espaldas del albergue de Paseo del Rey, donde no habían podido ser alojados por falta de espacio. En las inmediaciones, en coches y furgonetas abandonados se alojaban otros. Más recientemente (noviembre, 1992), el asesinato de una ciudadana dominicana sacó a la luz pública la presencia de unos 70 dominicanos alojados en las ruinas de edificios abandonados - expropiados de los márgenes de la carretera Nacional VI, en obras de ampliación: la discoteca «Four Roses", la antigua guardería "Los Bambinos" y una nave vacía de la firma Renault, todos ellos entre los Kms. 910 de la carretera. También son frecuentes noticias de inmigrantes, sobre 
todo africanos, pernoctando en las estaciones de metro de la capital, junto a mendigos e indigentes españoles.

Fuera de estas situaciones, los inmigrantes en situación precaria que duermen bajo techo recurren al chabolismo en una doble forma:

- la chabola, cabaña o cualquier estructura aprovechada como alojamiento, que aislada o formando poblados ocupa un espacio "visible", y

- lo que ha venido a denominarse "chabolismo vertical»: pisos sin condiciones de habitabilidad mínimas, que son otra forma de infravivienda localizada en edificios dentro de la trama urbana de la ciudad o de los pueblos del área metropolitana.

\subsection{El "chabolismo horizontal"}

Cuevas, chamizos, establos, naves, garajes y chabolas dispersas, sin agua ni luz, son situaciones de alojamiento presentes sobre todo en los municipios del Noroeste de Madrid, destacando Majadahonda, Boadilla del Monte, Villanueva de Pardillo, Valdemorillo, Fresnedillas, Pozuelo y Collado Villalba, en una línea que arranca del área de expansión residencial metropolitana para clases acomodadas, hacia los municipios de segunda residencia de la sierra.

Esta zona ha venido a ser asentamiento de población marroquí. En algunos de estos municipios existen pequeñas agrupaciones de viviendas de autoconstrucción dentro de fincas rústicas: las "casas de Diego", en Majadahonda, han sido noticia en varias ocasiones, por la quema y destrucción de chabolas que han sufrido (El País, 10 febrero 1992; 30 noviembre 1992...). En Villaviciosa de Odón algunos marroquíes se alojan en cuevas (El Pais Domingo, 22 noviembre, 1992).

También existen asentamientos de gitanos portugueses: así en la zona de la sierra, entre los términos de Collado Mediano, Guadarrama y Alpedrete, existe un asentamiento conocido como «poblado de la curva de la muerte", que alberga a un buen número de familias que se encuentran en condiciones de extrema necesidad.

Fuera de este área, en la zona Este, dentro del municipio de Madrid, se detectaba recientemente un asentamiento de siete familias croatas, casi todos gitanos de raza, en "Las Cárcavas", distrito de Hortaleza, viviendo en caravanas y tiendas de campaña, junto a un poblado gitano, sin luz ni agua ( $A B C, 5$ diciembre, 1992).

Existen áreas de chabolas de mayor amplitud. El Poblado de Ricote, en el distrito madrileño de Fuencarral es posiblemente el asentamiento 
más importante y el que más preocupa a la Administración, por considerarse el primer gueto de la comunidad. Ricote fue un poblado gitano de menores dimensiones, que formaba parte de un área de asentamientos chabolistas denominada genéricamente "La Veguilla", situada a caballo entre los distritos de Fuencarral, Moncloa y Tetuán. El Censo de Chabolas realizado en 1986 por el Consorcio para el Realojamiento de la Población Marginada arrojaba un total de 45 chabolas en la zona. Un nuevo censo del mismo organismo a 31 de diciembre de 1992 daba como resultado 17 chabolas "legales", es decir, de las censadas en 1986, en diseminado y 191 «ilegales", creadas en este período, todas ellas concentradas en el poblado de Ricote y habitadas - excepto una - por población marroquí.

Ricote en su inicios fue gitano y más pequeño. Ante la presión marroquí, los propietarios de las chabolas fueron alquilándolas a los inmigrantes y construyendo otras de nueva planta. Algunos sucesos desgraciados ocurridos en la zona a finales de 1991, tuvieron como consecuencia el alejamiento temporal de los gitanos del poblado; a su regreso, unos meses después, éste estaba ocupado en su totalidad por los marroquíes. Tras un corto período de convivencia, los gitanos lo abandonaron definitivamente. Las nuevas chabolas han sido construidas por los propios marroquíes, entre los que se encuentra una familia dedicada a ello.

Existen otros asentamientos chabolistas de importancia dentro del término de Madrid. En el mismo distrito de Fuencarral, en las proximidades del apeadero de Pitis, se encuentra el núcleo chabolista del mismo nombre, ocupado por población gitana portuguesa. Fuera del término, existen otros asentamientos de gitanos portugueses, en San Fernando de Henares, al Este y en Móstoles, al sur.

\section{2. "Chabolismo vertical»}

El casco histórico de Madrid, degradado en muchas zonas y con una alta proporción de edificios de antigua construcción, cuenta con una oferta crecida de viviendas de bajas condiciones de habitabilidad e infraviviendas: abundancia de pisos con una superficie inferior a $31 \mathrm{~m}^{2}$, auténticos tabucos sin retrete, sin ventilación y sin luz natural. Son con frecuencia el resultado de la ocupación en superficie y altura de parcelas pequeñas y estrechas no aptas para ser edificadas de forma intensiva. La especulación es la responsable.

La escasa renovación de las viviendas a lo largo del tiempo, por envejecimiento y falta de recursos de la población residente, ha dado como resultado su pervivencia en el momento actual, con un alto grado de deterioro. 
El "chabolismo vertical» ha sido denunciado recientemente por los equipos encargados de los estudios previos a la realización de un Proyecto de Rehabilitación del Casco Histórico de Madrid. Constituye uno de los problemas más importantes que tiene el centro de la ciudad, del que la prensa se ha hecho eco.

Este tipo de viviendas en alquiler es el escogido por los inmigrantes extranjeros en situación precaria. Desde el punto de vista del propietario, configuran la mejor clientela posible, ya que por sus dificultades de encontrar vivienda están dispuestos a aceptar cualquier condición. Al inmigrante se le puede pedir un alquiler más alto que al nacional, puesto que paga sin protestar, reuniendo el dinero a base de compartir el piso con otros compañeros.

Así, tabucos sin condiciones mínimas de habitabilidad se están alquilando a inmigrantes extranjeros en Lavapiés y el Rastro, por ejemplo, a 60.000 y 80.000 pesetas al mes, cantidad que un nacional nunca pagaría.

La sobreocupación de los pisos se produce por los abusivos precios de los alquileres y el estricto plan de ahorro del inmigrante, que no está dispuesto a gastar demasiado en sus necesidades personales para enviar el máximo a su familia. Además, su solidaridad intragrupo, por la que el que ha conseguido una vivienda acoge al que no la tiene, agrava la situación.

Así, a las bajas condiciones de habitabilidad de las viviendas alquiladas por inmigrantes extranjeros de bajos recursos, se une el hacinamiento, empeorando la circunstancia considerablemente.

Este tipo de vivienda no sólo se da en el centro de Madrid. También se denuncian casos en otros distritos de la ciudad y en municipios del área metropolitana. Sin embargo, el caso histórico es el espacio de concentración mayor.

Otra situación de alojamiento del colectivo inmigrante son las pensiones, que con frecuencia tienen idénticas condiciones ínfimas de habitabilidad que los pisos de alquiler, situándose como espacio privilegiado en el centro de Madrid sobre todo.

Hay 1.327 establecimientos de hostelería registrados en la Comunidad de Madrid. De ellos, 990 pensiones se sitúan en el centro (El País, 9 mayo 93). Esta cifra no cubre las ilegales que proliferan en el área: «el Centro de Madrid es el reino de las pensiones. Al tiempo que se degrada él, ellas van parejas... Dormir en algunas es una repugnante aventura" (Ibidem). El pasado año, el $80 \%$ de las quejas ante la Dirección General de Turismo de la CAM recayó sobre las pensiones, upor sus condiciones de habitabilidad o salubridad". 
El precio de ellas es de entre 500 y 2.000 pesetas/día, lo que explica que sean ocupadas con preferencia por inmigrantes en situación económica precaria.

Como ocurre con los pisos, las bajas condiciones de habitabilidad de las pensiones se agravan con el hacinamiento. En la pensión "Viguesa", situada en la calle Mesón de Paredes, «se alojaban hace dos años alrededor de 40 senegaleses. Cada uno pagaba entre 10.000 y 15.000 pesetas al mes y compartía la habitación con cuatro o cinco personas" (PERALES, J.A. 1992). La policía de la zona considera que «el problema es con los ilegales. Aceptan cualquier condición y a veces son ellos mismos los que meten a compatriotas en su habitación" (El País, 9 mayo 93).

La pensión como alojamiento es una forma de vivienda escogida sobre todo por solicitantes de asilo y refugio procedentes de África (LIZAMA, L. 1992; Perales, J.A. 1992).

\section{LA OFERTA INSTITUCIONAL}

Residencias y albergues son una oferta de alojamiento dirigida fundamentalmente a solicitantes de refugio y asilo en la CAM y financiada y gestionada por el Inserso y Cruz Roja.

El Inserso tiene en la CAM dos Centros de Acogida a Refugiados (C.A.R.) en Vallecas y Alcobendas, con un número aproximado de 100 plazas cada uno; 65 plazas concertadas con Cruz Roja para solicitantes de refugio en el hostal "Las Golondrinas" de Robledo de Chavela y 18 plazas con la CCEM en el chalet-residencia de la C/ Sierra 6. Financia en su programa para 1993 con cargo al 0,5\% del IRPF, en torno a 250 plazas más para el mismo colectivo en albergues gestionados por Cruz Roja o en pisos gestionados por ONGs (Fedora, Karibú y Ascriluz). Cuenta además con una residencia para menores solos, tutelada por los padres mercedarios (C/ Castelar 21), con 10 plazas. Por último, forma parte, junto con la Dirección General de Migraciones y las Fundaciones Gumiel y de Integración iberoamericana, del patronato que gestiona la recién construida Residencia «El Retorno" de Valdeolmos-Alalpardo, con 60 camas y destinada a los "niños de la guerra" - dentro del programa de emigrantes y exiliados retornados-, que ha demostrado su utilidad para acoger a grupos de inmigrantes recientemente, en el caso de los dominicanos de Aravaca.

Cruz Roja dirige su atención al mismo colectivo y lleva directamente albergues y residencias: así, el hostal "Las Golondrinas", con 65 plazas financiadas por el Inserso, que actúa como residencia. Recientemente, 
tras la demolición en noviembre de 1992 de uno de los dos albergues localizados en el madrileño Paseo del Rey, cedido por el Ayuntamiento de Madrid en 1990 a este organismo (60 plazas), se ha hecho cargo de la explotación del antiguo centro escolar "Agustín de Foxá" en San Blas, propiedad del Ayuntamiento y convertido en residencia en el mes de diciembre; también se destina a solicitantes de refugio, con 180 plazas, aunque las plazas no cubiertas pueden ser ocupadas por inmigrantes extranjeros.

No existe una oferta de este tipo dirigida en exclusividad a inmigrantes económicos. El Ayuntamiento de Madrid no tiene programas de realojo, sin embargo, cuenta con dos albergues para población transeúnte a los que acuden inmigrantes extranjeros en condiciones marginales. El Albergue "San Isidro", con una capacidad de en torno a 150 plazas, en el Paseo del Rey, estuvo ocupado en un $50 \%$ por extranjeros durante el año 1992. La proporción de éstos ha descendido a un $30 \%$ en lo que va de año. El «Pabellón del Frío" de la Casa de Campo, propiedad también del Ayuntamiento y gestionado por la empresa privada "Grupo 6", tiene 65 camas y está abierto únicamente de noviembre a marzo. También a él acude población extranjera.

Con la llegada de población desplazada de la antigua Yugoslavia, algunos ayuntamientos se han movilizado para su acogida. En Leganés el colegio "Numancia" se ha convertido desde diciembre de 1992 en refugio de un centenar de bosnios de origen musulmán.

Las ONGs, con menos posibilidades económicas, ejercen un importante papel de acogida. La Delegación Diocesana de Inmigrantes ofrece el albergue "Los Olivos", para población transeúnte, con veinte camas disponibles. Congregaciones Religiosas, como los Misioneros Combonianos, Misioneras Combonianas, Hnas. del Amor de Dios, Hijas del Patrocinio de María y Damas Apostólicas, acogen a inmigrantes. También en algunas parroquias - como "Virgen de la Candelaria" en San Blas- se acoge a esta población.

Las acciones de mediación entre propietarios de viviendas e inquilinos, para los contratos de arrendamiento, son soluciones puestas en marcha por las ONGs desde hace algunos años en Madrid. Hoy por hoy constituyen uno de los modelos a seguir en orden a resolver el rechazo de los propietarios de las viviendas, sobre todo en lo que se refiere a la población de color. Cruz Roja, la Delegación Diocesana de Inmigrantes y algunas asociaciones, como Karibú, tienen pisos para inmigrantes económicos y solicitantes de refugio, que ceden gratuitamente durante un período de tiempo, mientras el inmigrante inicia su integración y ahorra para acceder 
a un piso en propiedad o puede instalarse por su cuenta en un piso en alquiler. Esta fórmula ha demostrado ser útil y beneficiosa.

\section{POLITICAS DE VIVIENDA PARA INMIGRANTES EXTRANJEROS EN SITUACIÓN PRECARIA}

La fragmentación de la información sobre el tema de la vivienda de los inmigrantes más desfavorecidos en la CAM es una circunstancia negativa para el conocimiento del problema global. Resulta imprescindible una información de base actualizada sobre chabolismo e infravivienda que abarque el conjunto de la Comunidad, para establecer una política general.

La atomización de competencias y la inexistencia de directrices claras que delimiten la responsabilidad de cada uno de los organismos de la Administración implicados en el tema, hace muy difícil, por otra parte, la realización y puesta en marcha de un proyecto que tienda a resolver el problema. Las partes implicadas son la Administración central - con varios ministerios afectados, directa o indirectamente--, la Comunidad de Madrid y los ayuntamientos de todos los municipios del territorio.

La situación se agrava cada día con la llegada de nuevos contingentes de inmigrantes y solicitantes de refugio, a pesar del freno que ha supuesto la exigencia de visado a la población procedente de determinados países y el plan de cupos para trabajadores inmigrantes que se pondrá en marcha próximamente.

Mientras tanto, una buena parte del colectivo que consiguió legalizar su situación en la última regularización, empieza a pasar a la ilegalidad, al caducar sus permisos de trabajo y residencia, sin conseguir reunir las condiciones para renovarlos.

Pero no todo es negativo. Representantes de la Delegación del Gobierno, la Comunidad, el Ayuntamiento de Madrid y once ayuntamientos del Noroeste de la capital, además de algunas de las ONGs que trabajan con inmigrantes, iniciaron conversaciones en los últimos meses. Los problemas a resolver con preferencia son el gueto de Ricote y el alojamiento de los marroquíes asentados en los pueblos del Noroeste.

Fruto de estas conversaciones es la puesta en marcha recientemente del programa "Provivienda" por parte de la Consejería de Integración Social de la Comunidad de Madrid: se trata del realojo de chabolistas en pisos captados y gestionados por una empresa privada, con aval de la comunidad. El programa, inspirado y llevado a cabo conjuntamente con 
otro de parecidas características orientado a la juventud, parece estar teniendo poco éxito. Quizá los altos precios de los alquileres, unido al hecho de no permitirse la sobreocupación de los pisos y a su aún corta difusión, sean los factores decisivos.

Otras políticas de realojo que se podrían seguir, inspiradas en los pisos tutelados de las ONGs o en fórmulas de alquiler módicas con opción a compra -como apunta C. Giménez (1992) en un estudio realizado para la Comunidad de Madrid, entre las posibles soluciones al problema-, no parecen fáciles de aplicar por el momento, dada la existencia de otros colectivos nacionales desfavorecidos. El agravio comparativo podría atizar la xenofobia.

En la misma CAM existe un proyecto en estudio de erradicación de las chabolas, construyendo, como paso intermedio a la solución de los pisos, sanquis o módulos prefabricados dispersos en el territorio de varios municipios, cuyos ayuntamientos habrán de ceder los terrenos.

Ya se han adjudicado cinco módulos prefrabricados a Majadahonda y Boadilla del Monte y uno a las Rozas, Villanueva de la Cañada y Villanueva del Pardillo. Los restantes doce módulos en proyecto serán aportados por el sindicato UGT, que también ha decidido sumarse al programa de realojo.

Los módulos constarán de dos albergues vivienda, con una capacidad para dieciséis personas. Tendrán acceso a ellos 300 marroquíes, pagando 7.500 pesetas al mes y comprometiéndose a formar parte de un programa de realojo ( $A B C, 3$ julio 1993).

Dentro del marco de erradicación del chabolismo, se encarece a los ayuntamientos a la vigilancia en sus términos, para evitar nuevas construcciones de chabolas.

Por último, también existe en la comunidad la idea de la creación de un albergue para inmigrantes, como transición al realojo en pisos. En nuestra opinión, la conversión de centros escolares cerrados en albergues o residencias, sería la solución más fácil, rápida y barata, en este sentido. El precedente está en los colegios "Agustín de Foxá" y "Numancia».

En conclusión, el problema es difícil de resolver. Sin embargo, parece que se pueden estar poniendo los cimientos a una política de soluciones. La coordinación de las administraciones implicadas; la infraestructura ya creada de un gran número de ONGs que llevan años trabajando con los inmigrantes, conocen de cerca su problemas y tienen en marcha programas de integración y vivienda; el contacto con otros países que han vivido parecidas situaciones con anterioridad y cuyas soluciones podrían servir 
de modelos, son algunas de las circunstancias favorables que permiten creer que aunque tarde, aún se puede estar a tiempo.

\section{FUENTES Y BIBLIOGRAFIA}

Este artículo se basa en la información facilitada por

- la Concejalia de Servicios Sociales del Ayuntamiento de Madrid;

- la Consejería de Integración Social de la CAM;

- el Consorcio para el Realojamiento de la Población Marginada;

- el Inserso;

- la Cruz Roja;

- el INE

- algunas ONGs.

Fuente fundamental ha sido la prensa diaria, cuyas noticias han sido seleccionadas $y$ contrastadas.

Bibliografía básica:

- GaviRIA, M. (1992): “Contradicción entre los precarizados y los excluidos españoles y los inmigrantes económicos", Alfoz n. ${ }^{\circ}$ 91-92, págs. 134-137.

- Giménez Romero, C. (1992): Madrid y el desafío de la inmigración. Conclusiones del proyecto de investigación «Dimensionamiento y análisis por grupos étnicos de la Población inmigrante del Tercer Mundo y Portugal en la Comunidad Autónoma de Madrid". Consejería de Integración Social de la CAM, 101 págs. (en prensa).

- Lizama Fuentes, L. (1992): Inmigrantes marginados en Madrid. Ayuntamiento de Madrid, 247 págs. (Inédito).

- Perales Díaz, J.A. (1992) : “La vivienda y los inmigrantes en Madrid", Alfoz n. ${ }^{\circ} 91-92$, págs. 148-157.

Mi sincero agradecimiento a Pilar Ariño, Raquel Martín, Concepción Arroyo, Carmen García Oveja, Manoli Cela, Isabel Maldonado y Angeles Lora-Tamayo, miembros de los organismos arriba citados, y a Manuel Santiago, María del Carmen Martín Guinea y María del Carmen Pérez Delgado, cuya colaboración en la recogida de información de la prensa diaria ha sido de vital importancia.

Este artículo corresponde a la comunicación presentada a las Cuartas Jornadas de la Población Española celebradas en la Laguna de Tenerife entre los días 16 y 18 de junio de 1993, con el nombre de alnmigrantes y marginación social en Madrid».

Dicha comunicación es una versión resumida del texto que integramente se presenta aquí. 